\title{
Antihypertensive and hypolipidemic effect of milk fermented by specific Lactococcus lactis strains
}

\author{
J. C. Rodríguez-Figueroa, ${ }^{*} †$ A. F. González-Córdova, ${ }^{*}$ H. Astiazaran-García,‡ A. Hernández-Mendoza, ${ }^{*}$ \\ and B. Vallejo-Cordoba*1 \\ *Laboratorio de Química y Biotecnología de Productos Lácteos, Coordinación de Tecnología de Alimentos de Origen Animal, Centro de \\ Investigación en Alimentación y Desarrollo A.C. (CIAD), Carretera a La Victoria Km. 0.6 Hermosillo, Sonora 83304, Mexico \\ †Departamento de Tecnología de Alimentos de Origen Animal, Facultad de Zootecnia y Ecología, Universidad Autónoma de Chihuahua, \\ Periférico Francisco R. Almada Km. 1, Chihuahua, Chihuahua 33820, Mexico \\ łLaboratorio de Patología Experimental, Coordinación de Nutrición Centro de Investigación en Alimentación y Desarrollo A.C. (CIAD), \\ Carretera a La Victoria Km. 0.6 Hermosillo, Sonora 83304, Mexico
}

\begin{abstract}
The antihypertensive and hypolipidemic effects of milk fermented by specific Lactococcus lactis strains in spontaneously hypertensive rats (SHR) were investigated. The SHR were fed ad libitum milk fermented by Lc. lactis NRRL B-50571, Lc. lactis NRRL B-50572, Captopril $(40 \mathrm{mg} / \mathrm{kg}$ of body weight, Sigma-Aldrich Co., St. Louis, MO) or purified water for 4 wk. Results suggested that Lc. lactis fermented milks presented a significant blood pressure-lowering effect. No significant difference was noted among milk fermented by $L c$. lactis NRRL B-50571 and Captopril by the second and third week of treatment. Additionally, milk fermented by Lc. lactis strains modified SHR lipid profiles. Milk fermented by Lc. lactis NRRL B-50571 and B-50572 were able to reduce plasma low-density lipoprotein cholesterol and triglyceride contents. Thus, milk fermented by Lc. lactis strains may be a coadjuvant in the reduction of hypertension and hyperlipidemia and may be used as a functional food for better cardiovascular health.
\end{abstract}

Key words: Lactococcus lactis, fermented milk, antihypertensive effect, hypolipidemic effect

\section{INTRODUCTION}

Coronary heart disease (CHD) is the single largest cause of death in developed countries (Chobanian et al., 2003). Hypertension and elevated blood cholesterol levels, particularly high low-density lipoprotein cholesterol (LDL-C), are 2 of the major modified risk factors for the development of CHD (Department of Health and Human Services, 2000).

Received July 31, 2012.

Accepted January 13, 2013

${ }^{1}$ Corresponding author: vallejo@ciad.mx
Dairy proteins are potential ingredients in functional foods, as they may act as precursors of bioactive peptides with different physiological benefits on the human body (Korhonen, 2009). One way to increase the amount of bioactive peptides in dairy products is by milk fermentation with highly proteolytic strains of lactic acid bacteria (LAB; López-Fandiño et al., 2006) or by enzymatic hydrolysis with proteases from different sources (Tavares et al., 2011, 2012). Lactic acid bacteria present specific proteolytic systems for the generation of free AA and free peptides as a source of nitrogen required for their growth (Hugenholtz, 2008). Furthermore, peptides isoleucine-proline-proline and valine-proline-proline produced by Lactobacillus helveticus (LBK 16H strain) presented an antihypertensive effect in spontaneously hypertensive rats (SHR) after a long-term oral administration of the fermented milk (Sipola et al., 2002). Similarly, it has been shown that peptides released by Enterococcus faecalis strains from milk proteins were able to decrease arterial blood pressure in SHR (Muguerza et al., 2006; Quirós et al., 2007). However, to the best of our knowledge, the beneficial health effects of peptides in fermented milk with Lactococcus lactis strains have not been explored.

Lactococcus lactis is one of the most important LAB, as it generally takes the place of commercial starter cultures used in the manufacture of fermented dairy products (Odamaki et al., 2011). Lactococcus lactis strains are able to improve the organoleptic characteristics of dairy products, as they are responsible for the formation of volatile aroma compounds (Ayad, 2009). In fact, we were able to characterize Lc. lactis strains isolated from nature that produce characteristic cheese-like and yogurt-like aroma profiles in fermented milk (GutiérrezMéndez et al., 2008). Additionally, our research group demonstrated that Lc. lactis strains NRRL B-50571 and NRRL B-50572 were able to release several novel angiotensin I-converting enzyme-inhibitory peptides in fermented milks (Rodríguez-Figueroa et al., 2012b). 
Furthermore, we also demonstrated that whey fractions of these fermented milks showed an acute antihypertensive and heart rate-lowering effect in SHR after receiving a single dose (Rodríguez-Figueroa et al., 2012a).

The use of animal models to study the effect of food derived substances on CHD has been quite accepted nowadays. An SHR is characterized as presenting hyperlipidemia, hypertension, hyperinsulinemia, and type 2 diabetes (Brown et al., 2011). These characteristics made SHR one of the most useful models, besides the similarity of the pathologies mechanisms in humans (Doggrell and Brown, 1998). Therefore, several studies have been focused on the evaluation of antihypertensive and hypolipidemic effects of functional foods in SHR (Manso et al., 2008) and human subjects (Turpeinen et al., 2009; Pal et al., 2010). However, the antihypertensive and hypolipidemic effects of long-term consumption of fermented milk with specific Lc. lactis strains have not been tested. Thus, the objective of this research was to evaluate the antihypertensive and hypolipidemic effects of milk fermented by specific Lc. lactis strains through a long-term study with SHR.

\section{MATERIALS AND METHODS}

\section{Lc. lactis Strains}

Two Lc. lactis strains, NRRL B-50571 and NRRL B-50572, obtained from the Dairy Laboratory collection at Centro de Investigación en Alimentación y Desarrollo, A.C. (CIAD, Hermosillo, Sonora, Mexico) were deposited at the Agricultural Research Service Culture Collection (ARS, also known as the NRRL) from the US Department of Agriculture (Peoria, IL). The strains were propagated in $10 \mathrm{~mL}$ of sterile lactose $(5 \mathrm{~g} / \mathrm{L})$ M17 broth (Difco, Sparks, MD) and incubated at $30^{\circ} \mathrm{C}$ for $24 \mathrm{~h}$. Fresh precultures were obtained by repeating the same procedure allowing Lc. lactis strains to reach $10^{6}$ to $10^{7} \mathrm{cfu} / \mathrm{mL}$. The bacterial cell population was estimated by the pour-plate method using M17 agar containing lactose ( $5 \mathrm{~g} / \mathrm{L}$; Difco). To adapt bacteria to milk fermentation conditions, Lc. lactis working cultures were prepared by inoculating (1\%) fresh precultures in sterile $\left(100^{\circ} \mathrm{C}, 20 \mathrm{~min}\right)$ nonfat dry milk reconstituted $\left(10 \%\right.$, wt/wt) and incubated at $30^{\circ} \mathrm{C}$ for $12 \mathrm{~h}$.

\section{Sample Preparation}

An aliquot (3\%) of each working culture was obtained as described above and added to sterile skim milk to obtain the different fermented milk batches. Incubation was performed at $30^{\circ} \mathrm{C}$ over $48 \mathrm{~h}$. Then, the fermentation process was stopped by heating at $98^{\circ} \mathrm{C}$ for $10 \mathrm{~min}$ to inactivate proteases and Lc. lactis strains (Guan-Wen et al., 2007); subsequently, samples were frozen at $-20^{\circ} \mathrm{C}$. All fermented milk samples were unfrozen and homogenized daily (model 4169, Braun, Barcelona, Spain) for 20 min before use. Total protein (method 960.52; AOAC International, 2000), calcium, magnesium, potassium (EPA 3052), total fat (method 989.04; AOAC International, 2000), and lactose (method 930.28; AOAC International, 2000) contents were evaluated (Table 1).

\section{In Vivo Experimental Protocol}

Thirty-two male SHR were obtained from Harlan Laboratories Inc. (Indianapolis, IN). The rats were randomly housed in pairs per cage at $21 \pm 2^{\circ} \mathrm{C}$ with 12 -h light and dark cycles, $52 \pm 6 \%$ relative humidity, and with ad libitum intake of a standard diet (Teklad, Harlan Laboratories) during the experiment. Spontaneously hypertensive rats (27-28 wk old and $355 \pm 24 \mathrm{~g}$ of BW) were randomly split into 4 groups, each group included 8 animals $(\mathrm{n}=8)$. The first and second groups served as negative and positive controls and received purified water and Captopril (a proven hypotensive drug, $40 \mathrm{mg} / \mathrm{kg}$ of BW, Sigma-Aldrich Co., St. Louis, MO), respectively. The third and fourth groups were administered with milk fermented by Lc. lactis NRRL B-50571 and milk fermented by Lc. lactis NRRL 50572, respectively. All SHR had free access to each treatment during the $3 \mathrm{wk}$ as part of the protocol. Half of the animals of each group were killed at the end of that

Table 1. Nutritional composition of milks fermented by Lactococcus lactis NRRL strains

\begin{tabular}{lccc}
\hline Item & B-50571 & B-50572 & Food $^{1}$ \\
\hline Energy $(\mathrm{kcal} / 100 \mathrm{~g})$ & $62.4 \pm 0.5$ & $65.6 \pm 0.3$ & 307 \\
Protein $(\mathrm{g} / 100 \mathrm{~g})$ & $3.1 \pm 0.2$ & $3.3 \pm 0.1$ & 18.6 \\
Fat $(\mathrm{g} / 100 \mathrm{~g})$ & $\mathrm{ND}$ & $\mathrm{ND}$ & 6.2 \\
Carbohydrate $(\mathrm{g} / 100 \mathrm{~g})$ & $12.5 \pm 0.3$ & $13.1 \pm 0.2$ & 44.2 \\
Calcium $(\mathrm{mg} / 100 \mathrm{~g})$ & $368 \pm 11.3$ & $434 \pm 3.0$ & 1000 \\
Potasium $(\mathrm{mg} / 100 \mathrm{~g})$ & $439 \pm 14.6$ & $31.1 \pm 0.3$ & 200 \\
Magnesium $(\mathrm{mg} / 100 \mathrm{~g})$ & $32.2 \pm 1.2$ & & \\
${ }^{1}$ Data according to Teklad Global $18 \%$ protein rodent diet, Harlan Laboratories (Indianapolis, IN). \\
${ }^{2} \mathrm{ND}=$ not detected.
\end{tabular}


period. Meanwhile, the rest of the SHR only received purified water during one more week before being killed to determine a possible extended effect after cessation of the treatments. A research animal protocol was followed according to the guidelines established by the institutional ethics committee (CIOMS, 1985).

\section{Antihypertensive Effect Measurements}

The lowering blood pressure effect of milk fermented by specific Lc. lactis strains on SHR was monitored over time. Animals were deposited in restrainers in the warming chamber for $20 \mathrm{~min}$ at $32^{\circ} \mathrm{C}$ to detect pulsations through the caudal artery. Systolic (SBP) and diastolic (DBP) blood pressures were measured 5 times on each conscious animal before treatments and every week during the experiment. Measurements were obtained using the tail-cuff method between 9 and 12 $\mathrm{h}$ to eliminate circadian cycles. The noninvasive blood pressure system used in this experiment included a photoelectric sensor, an amplifier, an automatic inflation cuff, and software (model 229, IITC Life Science Inc., Woodland, CA).

\section{Plasma Lipid Profile Evaluation}

The hypolipidemic activity of milk fermented by specific Lc. lactis strains were also evaluated in SHR. Blood samples were collected under anesthesia by cardiac puncture in tubes with heparin (Sarstedt AG \& Co., Nümbrecht, Germany). Subsequently, samples were centrifuged at $756 \times g, 4^{\circ} \mathrm{C}$ for $10 \mathrm{~min}$ to obtain the plasma and they were frozen at $-20^{\circ} \mathrm{C}$ for further studies. Triglycerides (TG), total cholesterol, and highdensity lipoprotein cholesterol levels in plasma were determined by a commercial kit (Randox Laboratories, Kearneysville, WV), whereas LDL-C was calculated by the formula $\mathrm{LDL}=\mathrm{TC} / 1.19+\mathrm{TG} / 1.9-\mathrm{HDL} / 1.1-$ 38, as reported by Ahmadi et al. (2008).

\section{Statistical Analysis}

Normality of experimental data was evaluated as a prerequisite for the analysis by one-way ANOVA. Differences between means were assessed by the TukeyKramer multiple-comparison test and they were considered significantly different when $P<0.05$. Results were processed by the NCSS 2007 statistical program (NCSS Inc., Kaysville, UT). Data were presented as means \pm SEM.

\section{RESULTS AND DISCUSSION}

Nutritional composition corresponding to fermented milks is presented in Table 1. Milk with Lc. lactis
NRRL B-50571 was not significantly different $(P>$ 0.05) from milk with $L$ c. lactis NRRL B-50572. One of the most important macronutrients in fermented milk, which is related to the antihypertensive activity, may be the proteins. They eventually could be hydrolyzed by the proteolytic and peptidolytic systems of Lc. lactis strains to form hypotensive peptides (López-Fandiño et al., 2006). In fact, it was previously shown that the whey isolated from these fermented milk administered to SHR in a single dose was the fraction responsible for the blood pressure-lowering effect (Rodríguez-Figueroa et al., 2012a).

Conversely, the presence of calcium in dairy products has been associated to an antihypertensive effect (Jäkälä et al., 2009). However, only diets including $>2.5 \%$ of calcium reduce arterial blood pressure (Civantos and Aleixandre, 2004). In this study, the calcium contents in milk fermented by Lc. lactis NRRL B-50571 and Lc. lactis NRRL B-50572 were $368 \pm 11.3$ and $366 \pm 3.0$ $\mathrm{mg} / 100 \mathrm{~g}$, respectively, which is equivalent to only 0.81 and $0.83 \%$ in the diet. Thus, the effect of calcium could be disregarded.

Before the experiment, SHR (27-28 wk old) SBP and DBP were $226 \pm 3.2$ and $180 \pm 4.5 \mathrm{mmHg}$, respectively. Both Lc. lactis fermented milks were able to reduce blood pressure during the experiment (Figure 1 and 2). Results did not show significant differences $(P>0.05)$ between SBP measurements in the first week (Figure 1). However, by the second week, the SBP level was 20.2 $\mathrm{mmHg}$ lower in SHR that received milk fermented by Lc. lactis NRRL B-50571 than the group that received water $(233.3 \pm 1.8$ vs. $253.5 \pm 2.8 \mathrm{mmHg})$ and was not statistically different $(P>0.05)$ from those that received Captopril $(223.8 \pm 5.2 \mathrm{mmHg})$. In fact, by the second and third week, SHR treated with Captopril or milks fermented by Lc. lactis NRRL B-50571 presented a marked lowering effect on SBP. By the fourth week of treatment, SBP level was $23.3 \mathrm{mmHg}$ lower in SHR that received milk fermented by Lc. lactis NRRL B-50571 than the group that received water $(234.3 \pm$ 1.9 vs. $257.6 \pm 6.4 \mathrm{mmHg}$ ), and was not statistically different $(P>0.05)$ from those that received Captopril $(229.5 \pm 7.1 \mathrm{mmHg})$.

As observed in Figure 1, the SBP-lowering effect in SHR treated with milk fermented by Lc. lactis NRRL B-50571 increased with time when compared with SHR administered with water. Indeed, the maximal SBP reduction was found by the fourth week, even though animals drank only water in the last week. Thus, these results suggested an extended SBP-lowering effect after cessation of the treatment.

Diastolic blood pressure was also monitored as part of the experimental procedure. SHR treated with milk fermented by Lc. lactis NRRL B-50571 and B-50572 


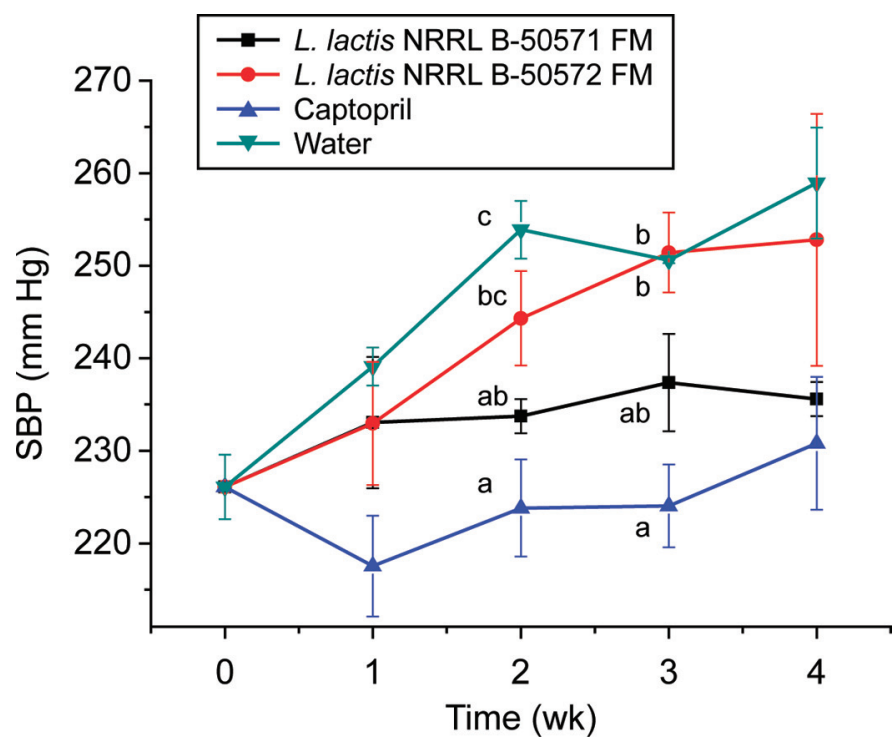

Figure 1. Systolic blood pressure (SBP) of spontaneously hypertensive rats subjected to different treatments. Lactococcus lactis NRRL B-50571 fermented milk (FM; ם); Lc. lactis NRRL B-50572 FM (-); Captopril (Sigma-Aldrich Co., St. Louis, MO) = positive control $(\mathbf{\Lambda})$; purified water $=$ negative control $(\mathbf{\nabla})$. Data are shown as mean values \pm SEM $(n=8)$. Data points sharing the same letter $(\mathrm{a}-\mathrm{c})$ within a week are not significantly different $(P>0.05)$. Color version available in the online PDF.

presented a DBP-lowering effect during the experiment (Figure 2). As in SBP, the first week, DBP measurements were not significantly different $(P>0.05)$ between treatments. However, by the second week, the DBP level was $24.5 \mathrm{mmHg}$ lower in SHR that received milk fermented by Lc. lactis NRRL B-50571 than the group that received water $(207.2 \pm 2.0$ vs. $231.7 \pm$ $3.2 \mathrm{mmHg})$ and was not statistically different $(P>$ 0.05) from those that received Captopril (193.2 \pm 5.3 $\mathrm{mmHg}$ ). Furthermore, by the third experimental week, the DBP-lowering effect was not significantly different $(P>0.05)$ between SHR treated with Captopril and milk fermented by Lc. lactis NRRL B-50571 or B-50572. The most important DBP reduction, $49.8 \mathrm{mmHg}$, was observed in the fourth week of treatment in SHR that received milk fermented by Lc. lactis NRRL B-50571 against those that received water $(184.3 \pm 4.6$ vs. 234.1 $\pm 2.6 \mathrm{mmHg}$ ).

These results were similar to those reported by others, who found that milk fermented by Lactobacillus helveticus $\mathrm{LBK} 16 \mathrm{H}$ was able to reduce SBP by 21 $\mathrm{mmHg}$ (Sipola et al., 2002). Also, it was shown that the milk tetrapeptide $\alpha$-lactorphin reduced SBP and DBP by $23 \pm 4$ and $17 \pm 4 \mathrm{mmHg}$, respectively, after being administered to SHR (Nurminen et al., 2000). Additionally, Jauhiainen et al. (2007) demonstrated the presence of a radiolabelled analog of the milk-derived

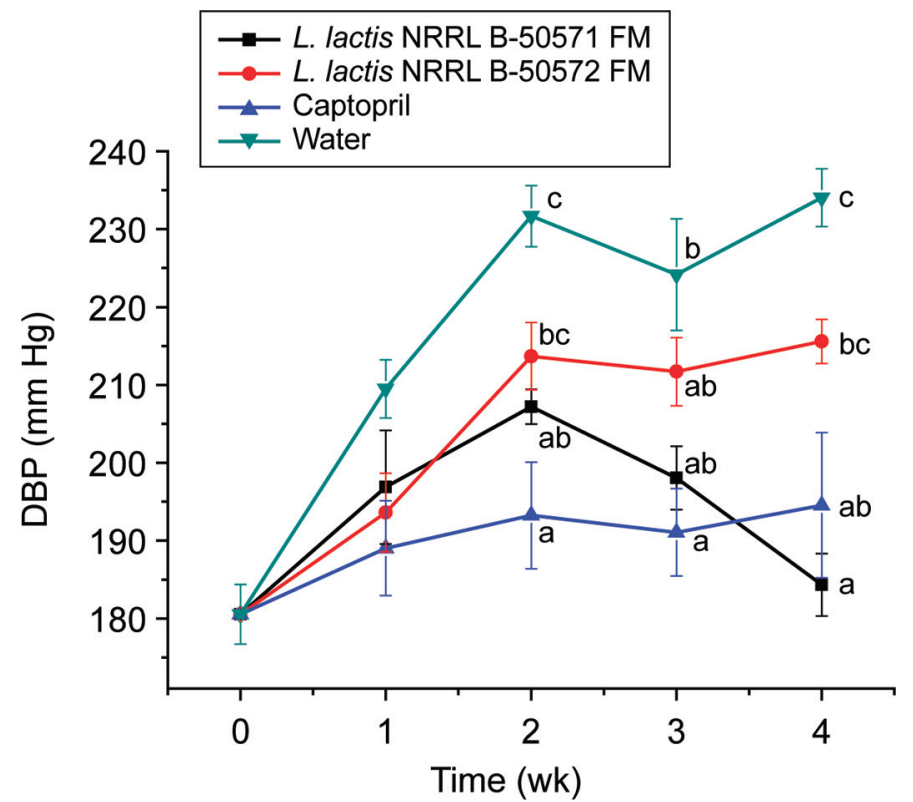

Figure 2. Diastolic blood pressure (DBP) of spontaneously hypertensive rats subjected to different treatments. Lactococcus lactis NRRL B-50571 fermented milk (FM; $\mathbf{~ ) ; ~ L c . ~ l a c t i s ~ N R R L ~ B - 5 0 5 7 2 ~ F M ~}$ (•); Captopril (Sigma-Aldrich Co., St. Louis, MO) = positive control $(\boldsymbol{\Lambda})$; purified water $=$ negative control $(\boldsymbol{\nabla})$. Data are shown as mean values $\pm \operatorname{SEM}(\mathrm{n}=8)$. Color version available in the online PDF.

antihypertensive peptide isoleucine-proline-proline in several rat tissues $48 \mathrm{~h}$ after a single oral administration. Therefore, fermented milk containing antihypertensive peptides administered for long periods may extend their bioactivity even after cessation of the treatment.

Results suggested that fermented milks were able to modify SHR lipid profiles by the third week of treatment. Spontaneously hypertensive rats that received milk fermented by Lc. lactis NRRL B-50571 presented an LDL-C of $27.1 \mathrm{mg} / \mathrm{dL}$, which is $8.4 \mathrm{mg} / \mathrm{dL}$ lower than the LDL-C of SHR administered with water (35.5 mg/dL; Table 2). Similarly, SHR that received milk fermented by Lc. lactis NRRL B-50572 presented an LDL-C of $13.6 \mathrm{mg} / \mathrm{dL}$, which is $21.9 \mathrm{mg} / \mathrm{dL}$ lower than the LDL-C of SHR administered with water (35.5 $\mathrm{mg} / \mathrm{dL}$; Table 2). Furthermore, LDL-C values of SHR administered with fermented milks were significantly lower $(P<0.05)$ than those for SHR administered with Captopril (Table 2).

On the other hand, high-density lipoprotein cholesterol values were not significantly different $(P>0.05)$ in SHR administered with fermented milk or water or Captopril (Table 2). According to the National Cholesterol Education Program Adult Treatment Panel III, it is a priority to reduce LDL-C as a primary target to reduce the risk of heart disease and as a secondary target to reduce the risk of metabolic syndrome (Expert 
Table 2. Effects of fermented milks on serum lipids of spontaneously hypertensive rats ${ }^{1}$

\begin{tabular}{lcccc}
\hline Item & $\begin{array}{c}\mathrm{TC} \\
(\mathrm{mg} / \mathrm{dL})\end{array}$ & $\begin{array}{c}\text { TG } \\
(\mathrm{mg} / \mathrm{dL})\end{array}$ & $\begin{array}{c}\text { HDL-C } \\
(\mathrm{mg} / \mathrm{dL})\end{array}$ & $\begin{array}{c}\text { LDL-C } \\
(\mathrm{mg} / \mathrm{dL})\end{array}$ \\
\hline Lactococcus lactis NRRL B-50572 & $73.7 \pm 1.8$ & $25.7 \pm 1.5^{\mathrm{a}}$ & $26.2 \pm 1.6$ & $13.6 \pm 0.8^{\mathrm{a}}$ \\
Lactococcus lactis NRRL B-50571 $_{\text {Captopril }^{2}}$ & $75.2 \pm 1.9$ & $47.0 \pm 3.0^{\mathrm{b}}$ & $25.1 \pm 1.8$ & $27.1 \pm 5.2^{\mathrm{ab}}$ \\
Water $^{\mathrm{b}}$ & $76.1 \pm 3.2$ & $68.1 \pm 13.1^{\mathrm{c}}$ & $28.6 \pm 2.6$ & $35.8 \pm 3.9^{\mathrm{b}}$ \\
\hline
\end{tabular}

${ }^{\mathrm{a}-\mathrm{c}}$ Values within a column followed by different superscript letters are significantly different $(P<0.05)$.

${ }^{1}$ Data presented as mean $\pm \mathrm{SEM}$; TC $=$ total cholesterol; TG $=$ triglycerides; HDL-C $=$ high-density lipoprotein-cholesterol; LDL-C = low-density lipoprotein-cholesterol.

${ }^{2}$ Sigma-Aldrich Co., St. Louis, MO.

Panel on Detection, Evaluation, and Treatment of High Blood Cholesterol in Adults, 2001).

Spontaneously hypertensive rats that received milk fermented by Lc. lactis NRRL B-50571 presented a plasma TG content of $47.0 \mathrm{mg} / \mathrm{dL}$, which is $15 \mathrm{mg} /$ dL lower than the TG content of SHR administered with water $(62.0 \mathrm{mg} / \mathrm{dL}$; Table 2$)$. Similarly, SHR that received milk fermented by Lc. lactis NRRL B-50572 presented a plasma TG content of $25.7 \mathrm{mg} / \mathrm{dL}$, which is $36.3 \mathrm{mg} / \mathrm{dL}$ lower than the TG content of SHR administered with water $(62.0 \mathrm{mg} / \mathrm{dL}$; Table 2$)$. Furthermore, TG values of SHR administered with fermented milks were significantly $(P<0.05)$ lower than those for SHR administered with Captopril (Table 2). Additionally, plasma total cholesterol content was slightly reduced in SHR that received fermented milk, although differences were not significantly different $(P>0.05$; Table 2$)$.

It has been reported that milk supplemented with whey protein concentrate and fermented by Lactobacillus casei TMC0409 and Streptococcus thermophilus TMC1543 decreased serum TG from $151.7 \pm 13.9$ to $115.7 \pm 11.1 \mathrm{mg} / \mathrm{dL}$ in humans after 4 wk of treatment (Kawase et al., 2000). Even though lipid profiles of SHR treated with fermented milks were also evaluated after 1 wk treatment with purified water, no significant difference was observed among treatments $(P$ $>0.05)$. Thus, these results suggest that no extended hypolipidemic-lowering effect exists after cessation of the treatment.

It has been reported that nongrowing and dead cells of specific strains of the genus Lactococcus could remove cholesterol via binding of cholesterol to the cellular surface (Kimoto-Nira et al., 2007). These authors suggested that cholesterol was bound to the bacterial cells and this was a result of the chemical and structural properties of their cell wall peptidoglycans, which contain several AA that ease the attachment of cholesterol to the cells (Kimoto-Nira et al., 2007). Therefore, as $L c$. lactis cells were killed during the pasteurization treatment applied to fermented milk, the cholesterol lowering effect of this study may be attributed to cholesterol removal by attachment to cells, however, this remains to be determined. However, the lowering effect on LDL$\mathrm{C}$ due to the ingestion of dairy protein or peptides present in fermented milk could not be disregarded. It has been reported that obese and overweight individuals who consume whey protein for 12 wk presented an important reduction in LDL-C (Pal et al., 2010).

\section{CONCLUSIONS}

Milks fermented by specific Lc. lactis strains were able to reduce systolic SBP and DBP in an SHR. Moreover, the SHR lipid profile was improved by fermented milk intake for $3 \mathrm{wk}$, although the mechanism for this effect remains to be determined. The use of milk fermented by specific LAB may be considered as a coadjuvant for the improvement of cardiovascular health. To the best of our knowledge, this is the first in vivo study that showed the antihypertensive and hypolipidemic effects of continuous consumption of fermented milk with specific Lc. lactis strains. Thus, dairy products fermented with Lc. lactis strains NRRL B-50571 and NRRL B-50572 may be used as functional foods with potential benefits for cardiovascular health.

\section{ACKNOWLEDGMENTS}

We thank María del Carmen Estrada, Bertha I. Pacheco Moreno, Ana Cristina Gallegos, and Rodrigo Pacheco [all from Centro de Investigación en Alimentación y Desarrollo A.C. (CIAD), Sonora, Mexico] for their technical support during the experiment. This study was supported by the Mexican Council of Science and Technology (CONACYT; Mexico City, Mexico) research project 134295 CONACYT (Ciencia Básica Convocatoria 2009).

\section{REFERENCES}

Ahmadi, S. A., M. A. Boroumand, K. Gohari-Moghaddam, P. Tajik, and S. M. Dibaj. 2008. The impact of low serum tryglyceride on LDL-cholesterol estimation. Arch. Iran Med. 11:318-321. 
AOAC International. 2000. Official Methods of Analysis of AOAC International. 17th ed. AOAC International, Gaithersburg, MD.

Ayad, E. H. E. 2009. Starter culture development for improving safety and quality of Domiati cheese. Food Microbiol. 26:533-541.

Brown, L. M., C. T. Hansen, and A. F. Huberty. 2011. Traits of the metabolic syndrome alter corpulent obesity in LAN, SHR and DSS rats: Behavioral and metabolic interactions with adrenalectomy. Physiol. Behav. 103:98-103.

Chobanian, A. V., G. Bakris, H. Black, W. Cushman, L. Green, J. Izzo, D. Jones, B. Materson, S. Oparil, J. Wright, and E. Roccella.. 2003. The seventh report of the Joint National Committee on Prevention, Detection, Evaluation, and Treatment of High Blood Pressure. JAMA 289:2560-2572.

CIOMS (Council for International Organizations of Medical Sciences). 1985. International guiding principles for biomedical research involving animals. http://cioms.ch/publications/guidelines/1985_ texts_of_guidelines.htm.

Civantos, B., and A. Aleixandre. 2004. Blood pressure and $\alpha$-vascular reactivity in hypertensive rats treated with amlodipine and dietary Ca. Eur. J. Pharmacol. 489:101-110.

Department of Health and Human Services. 2000. Public Health Service, Healthy People 2010, Vol. I. US Government Printing Office, Washington, DC.

Doggrell, S. A., and L. Brown. 1998. Rat models of hypertension, cardiac hypertrophy and failure. Cardiovasc. Res. 39:89-105.

Expert Panel on Detection, Evaluation, and Treatment of High Blood Cholesterol in Adults. 2001. Executive summary of the third report of the National Cholesterol Education Program (NCEP). Expert panel on detection, evaluation, and treatment of high blood cholesterol in adults (Adult Treatment Panel III). JAMA. 285, 2486-2497.

Guan-Wen, C., T. Jenn-Shou, and P. Bonnie Sun. 2007. Purification of angiotensin I-converting enzyme inhibitory peptides and antihypertensive effect of milk produced by protease-facilitated lactic fermentation. Int. Dairy J. 17:641-647.

Gutiérrez-Méndez, N., B. Vallejo-Cordoba, A. F. González-Córdova, G. V. Nevárez-Moorillón, and B. Rivera-Chavira. 2008. Evaluation of aroma generation of Lactococcus lactis with an electronic nose and sensory analysis. J. Dairy Sci. 91:49-57.

Hugenholtz, J. 2008. The lactic acid bacterium as a cell factory for food ingredient production. Int. Dairy J. 18:466-475.

Jäkälä, P., T. Jauhiainen, R. Korpela, and H. Vapaatalo. 2009. Milk protein-derived bioactive tripeptides Ile-Pro-Pro and Val-Pro-Pro protect endothelial function in vitro in hypertensive rats. J. Funct. Foods 1:266-273.

Jauhiainen, T., K. Wuolle, H. Vapaatalo, O. Kerojoki, K. Nurmela, C. Lowrie, and R. Korpela. 2007. Oral absorption, tissue distribution and excretion of a radiolabelled analog of a milk-derived antihypertensive peptide, Ile-Pro-Pro, in rats. Int. Dairy J. 17:1216-1223.

Kawase, M., H. Hashimoto, M. Hosoda, H. Morita, and A. Hosono. 2000. Effect of administration of fermented milk containing whey protein concentrate to rats and healthy men on serum lipids and blood pressure. J. Dairy Sci. 83:255-263.

Kimoto-Nira, H., K. Mizumachi, M. Nomura, M. Kobayashi, Y. Fujita, T. Okamoto, I. Suzuki, N. M. Tsuji, J. I. Kurisaki, and S. Ohmomo. 2007. Lactococcus sp. as potential probiotic lactic acid bacteria. Jpn. Agric. Res. Q. 41:181-189.
Korhonen, H. 2009. Milk-derived bioactive peptides: From science to applications. J. Funct. Foods 1:177-187.

López-Fandiño, R., J. Otte, and J. van Camp. 2006. Physiological, chemical technological aspects of milk-protein-derived peptides with antihypertensive and ACE-inhibitoryactivity. Int. Dairy J. 16:1277-1293.

Manso, M., M. Miguel, J. Even, R. Hernández, A. Aleixandre, and R. López-Fandiño. 2008. Effect of the long-term intake of an egg white hydrolysate on the oxidative status and blood lipid profile of spontaneously hypertensive rats. Food Chem. 109:361-367.

Muguerza, B., M. Ramos, E. Sánchez, M. A. Manso, M. Miguel, A. Aleixandre, M. A. Delgado, and I. Recio. 2006. Antihypertensive activity of milk fermented by Enterococcus faecalis strains isolated from raw milk. Int. Dairy J. 16:61-69.

Nurminen, M.-L., M. Sipola, H. Kaarto, A. Pihlanto-Leppälä, K. Piilola, R. Korpela, O. Tossavainen, H. Korhonen, and H. Vapaatalo. 2000. $\alpha$-Lactorphin lowers blood pressure measured by radiotelemetry in normotensive and spontaneously hypertensive rats. Life Sci. 66:1535-1543.

Odamaki, T., S. Yonezawa, and H. Sugahara. 2011. A one step genotypic identification of Lactococcus lactis subspecies at the species/ strain levels. Syst. Appl. Microbiol. 34:429-434.

Pal, S., V. Ellis, and S. Dhaliwal. 2010. Effects of whey protein isolate on body composition, lipids, insulin and glucose in overweight and obese individuals. Br. J. Nutr. 104:716-723.

Quirós, A., M. Ramos, B. Muguerza, M. Delgado, M. Miguel, A. Aleixandre, and I. Recio. 2007. Identification of novel antihypertensive peptides in milk fermented with Enterococcus faecalis. Int. Dairy J. $17: 33-41$.

Rodríguez-Figueroa, J. C., A. F. González-Córdoba, H. AstiazaránGarcía, and B. Vallejo-Cordoba. 2012a. Hypotensive and heart rate-lowering effects in rats receiving milk fermented by specific Lactococcus lactis strains. Br. J. Nutr. http://dx.doi.org/10.1017/ S0007114512002115.

Rodríguez-Figueroa, J. C., A. F. González-Córdoba, M. J. TorresLlanez, H. S. García, and B. Vallejo-Cordoba. 2012b. Novel angiotensin I-converting enzyme inhibitory peptides produced in fermented milk by specific wild Lactococcus lactis strains. J. Dairy Sci. 95:5536-5543. http://dx.doi.org/10.3168/jds.2011-5186.

Sipola, M., P. Finckenberg, R. Korpela, H. Vapaatalo, and M.-L. Nurminen. 2002. Effects of long-term intake of milk products on blood pressure in hypertensive rats. J. Dairy Res. 69:103-111.

Tavares, T., M. M. Contreras, M. Amorim, M. Pintado, I. Recio, and F. X. Malcata. 2011. Novel whey-derived peptides with inhibitory effect against angiotensin-converting enzyme: In vitro effect and stability to gastrointestinal enzymes. Peptides 32:1013-1019.

Tavares, T., M. A. Sevilla, M. J. Montero, R. Carrón, and F. X. Malcata. 2012. Acute effect of whey peptides upon blood pressure of hypertensive rats, and relationship with their angiotensin-converting enzyme inhibitory activity. Mol. Nutr. Food Res. 56:316-324.

Turpeinen, A. M., M. Kampu, M. Rönnback, L. Seppo, H. Kautiainen, T. Jauhiainen, H. Vapaatalo, and R. Korpela. 2009. Antihypertensive and cholesterol-lowering effects of a spread containing bioactive peptides IPP and VPP and plant sterols. J. Funct. Foods 1:260-265. 